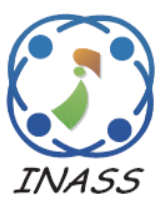

\title{
Development of Hybrid Teaching Method Using MOOCs
}

\author{
Myungsuk Lee ${ }^{1 *} \quad$ Eunsook Bae $^{1}$ \\ ${ }^{I}$ TabulaRasa College, Keimyung University, South Korea \\ * Corresponding author's Email: mslee@kmu.ac.kr
}

\begin{abstract}
The purpose of this study is to explore a new teaching and learning method using MOOC as a way of solving the change of the educational environment and the learner 's unsatisfied academic desire. This study suggests 'Hybrid teaching method' as a way to utilize MOOC in liberal arts education. This teaching method is a method of perfect learning through formal learning and informal learning. Formal learning consisted of a teacher - centered knowledge acquisition stage and a learner - centered thinking extension stage. Informal learning consists of learner - led experience/reflection stages. It is a characteristic of 'Hybrid teaching method' that emphasizes the role of instructor, breaks the boundaries of education space through informal learning, and implements perfect learning through level learning. This study is meaningful that the MOOC has provided a detailed plan to utilize it in the curriculum of the university. We hope that the 'Hybrid teaching method' using MOOCs will be a way to adapt and lead the liberal education to the future education trends as a customized learning according to the development of science and technology, destruction of spatial areas such as online and offline, emphasis on connection between theory and reality through formal learning and informal learning.
\end{abstract}

Keywords: Hybrid teaching method, Informal learning, Mastery learning, MOOC.

\section{Introduction}

The rapid stream of times in the 21 st century has led to the era of the '4th industrial revolution.' Following the internet-based 3rd industrial revolution, the 4th industrial revolution (Industry 4.0) is the era of technology revolution that combines digital industry, bio industry, physics, and so forth. The 4th industrial revolution is different from the previous $1 \mathrm{st}$ to 3rd industrial revolutions in that its speed and scope of change are unprecedented. Such technology revolution has changed learners' tendencies in the field of education. Today, learners are a generation called 'digital natives'. As this generation of digital natives grew over the 1990 s during which computers, mobile phones, and the internet became generalized, they think and communicate in a way that is totally different from those in the past. They are skillful not only in making use of IT techniques but also in finding necessary information for themselves via the internet and communicating with others by means of SNS. As they sense extemporaneously and simultaneously by using digital means, learners prefer core knowledge in the flood of change, promptness, and immensity. Hence, this age requires selection and concentration in order to note relevant knowledge in the vast amount of information.

Expanding liberal arts subjects and opening new convergence subjects result from the recognition that in the rapidly changing modern society, knowledge within the boundary of existing studies is of insufficiency. In response to the increasing need for talented individuals who are capable of accommodating and applying knowledge and technology regardless of majors, the importance of liberal education is to be ever more emphasized now.

Basically, the policies of the Ministry of Education focus on deepening basic studies and fostering convergence majors. The concept of convergence commonly stated among scholars is "a phenomenon that two or more of the existing but different academic knowledge or technology areas are combined physically or chemically to create a new, original value." The education of convergence makes it possible to create new, unique values 
through convergence that crosses the boundaries of two or more academic areas and thereby to train talented individuals capable of spreading such values over the academic circle, society, economy, and culture. Basic liberal education is a prerequisite of such training of talented persons. Accordingly, basic liberal education as well needs to be practiced in a way that pursues integrated thinking, supporting pure academic research, seeking practical education, and crossing the borders of the humanities, science, and engineering.

Learners have desires for various areas of learning. While seeking deep knowledge in a certain area, they long to obtain knowledge from various branches and develop creativity to utilize such knowledge. It is necessary to find a way to satisfy such academic desires among learners that have yet to be met in reflection of the changing education environment. In this regard, the present study is of significance as it seeks new teaching-learning methods in harmony with this era of change.

\section{Background}

\subsection{Current condition and evaluation of online open lectures}

The MOOC standards for the 'Massive Open Online Course.' While existing online lectures let learners listen merely passively, the MOOC is a lecture platform which makes possible various interactions such as inquiries and answers, discussions, quizzes, and assignments between teachers and learners or between learners. The MOOC has caused significant repercussions with its provision of free online open lectures by renowned college professors. Despite the shock that the MOOC brought about to colleges, however, the rate of using the MOOC in actual college lectures is low. In a survey that investigated the rate of utilizing Elearning contents at college in the year of 2015, the rate of using the MOOC was as low as $0.18 \%$. It is unable to predict the future of the MOOC due to the technical limitation at present. Although it is now at the 'low point of disappointment' in the hype cycle, developing tools with learning analysis and technical advancement will lead to the 'beginning of understanding.' In the future, the usability of the MOOC will increase and then colleges will have to pay more attention to the MOOC. Rather than rejecting or neglecting the MOOC in fear that it might swallow them, colleges should develop ways to utilize the MOOC to be prepared for the future. Developing specific plans to include the MOOC in college curriculums will be a genuine solution to sharing educational resources.

\subsection{MOOC utilization plan}

For the use of the MOOC in classes to be effective, teachers have to play their roles: Teachers need to provide learners with keen interest and advice so that they can be familiar with the MOOC. Interactions with learners and constant help for their direction of activity need to be part of offline classes. When the course of learners' activity deviates from the education goals, teachers need to correct them properly. Thus, the utilization of the MOOC is deeply related to the field progress in offline classes, and in this regard, the role of teachers is to be emphasized. In learner-centered learning with the MOOC utilized, the following aspects need to be considered:

First, teaching-learning methods need to be diversified. Teaching-learning methods that utilize video lectures are mostly flip learning and blended learning. There can be various kinds of learnercentered learning methods available in addition to flip learning and blended learning. Major examples are problem-focused learning, action learning, casefocused learning, objective-focused learning, projectfocused learning, team-centered learning, etc. Whether it is individual learning or cooperative learning, various teaching-learning methods need to be attempted to find those inducing voluntary, selfdirected learning among learners with their significant educational effects.

Second, the role of teachers needs to be strengthened. In learner-centered learning, teachers can interact with learners throughout class sessions. For this purpose, teachers need to include advance learning in class designing rather than leaving advance learning merely to learners. Class designing should include selecting and reorganizing class contents, selecting teaching/learning activities for advance learning, selecting teaching/learning activities for lecture room classes, establishing strategies for efficient learner-centered learning, and so forth.

For the MOOC-based classes to be effective, the role of teachers is vital. Teachers need to spare no interest and advice for the proper acquisition of the MOOC. In offline classes, interactions with learners and constant help for their direction of activity need to be part of offline classes. When the course of learners' activity deviates from the education goals, teachers need to correct them properly. Thus, the utilization of the MOOC is deeply related to the field progress in offline classes, and in this regard, the role of teachers is to be emphasized. 


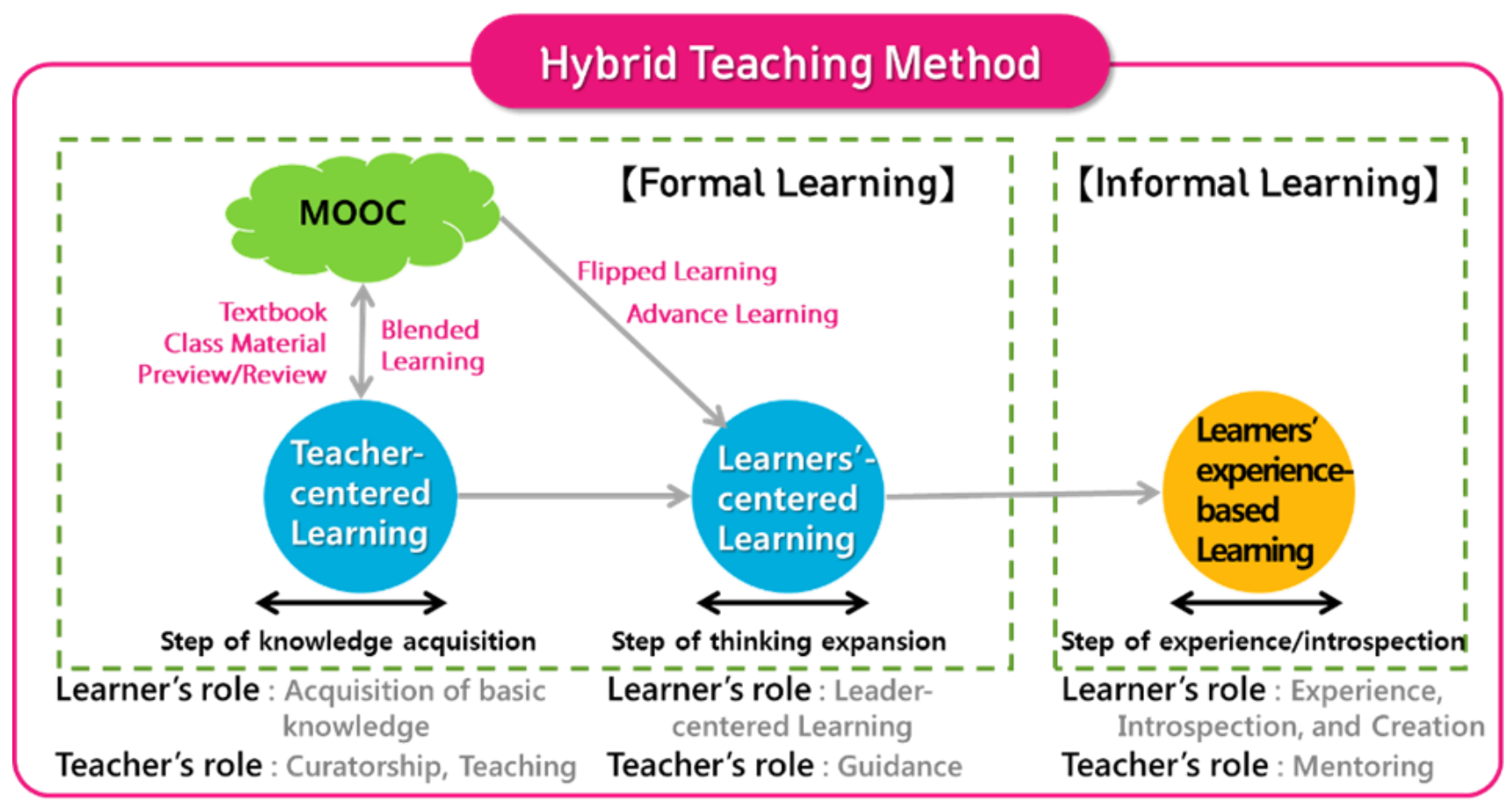

Figure.1 The model designed for the hybrid teaching method

The MOOC may be connected to informal learning. In the context of a learning process, informal learning is basically to understand a leaner's specific experience in life and to impart a unique meaning to that experience through logical inference and interpretation. Thus, informal learning is an object of meaning interpretation and a beginning point of introspection activity. As a learner's cognitive activity for and regarding 'experience,' 'introspection' is of great importance in understanding the concept of informal learning.

Although mastery learning is the ultimate pursuit of education objectives, achieving it is difficult in reality. Since the level of understanding class content, aptitudes, and tendencies are varied among learners, it is difficult to achieve mastery learning in a school environment where learning time and space is fixed. For this reason, the theory of mastery learning failed to draw attention for a long time although it was an attractive theory. As advanced technology develops in the 21st century, however, the theory of master learning, which was regarded as impossible to achieve in the 20th century, is taking a new turn. The feasibility of mastery learning has now come to the fore. As long as learners can learn from lectures at the rate and level that they want through the MOOC, it will be possible to achieve education objectives that teachers seek. In addition, teachers may reorganize MOOC lecture contents according to their curriculums and include such contents in their lectures presented at the lecture room. To enhance the understanding of lecture contents among learners, teachers may design learner-centered activities that help improving learners' recognition and knowledge. Once learners participate in activities of knowledge acquisition and thinking expansion, they may satisfy other intellectual desires through experience and introspection in daily life.

\section{Hybrid teaching method}

\subsection{Definition of the hybrid teaching method}

This study aims to develop a 'hybrid teaching method' by inducing advantages of existing flip learning and blended learning that utilize online video lectures and making up for their disadvantages. One advantage of these two teaching-learning methods is that they make possible learners' selfdirected learning. Disadvantages include insufficiency of learning density, professors' feedbacks, class concentration, etc. The hybrid teaching method is defined as an integration of formal and informal learning with the steps of experience/introspection and on/offline integrated education applied.

\subsection{A model for hybrid teaching method designing}

The model designed in this study for the hybrid teaching method distinguishes formal learning from informal learning. In formal learning, the MOOC is utilized for preview/review. After the formal learning, learners practice informal learning on the given subject freely, that is, experience/introspection. 
Table 1. Steps of learning and class activity

\begin{tabular}{|c|c|c|}
\hline $\begin{array}{c}\text { Step of } \\
\text { Learning }\end{array}$ & $\begin{array}{c}\text { Step of Class } \\
\text { Activity }\end{array}$ & Description \\
\hline \multirow[b]{2}{*}{ Pre-class Step } & $\begin{array}{l}\text { Learner Level } \\
\text { Assessment }\end{array}$ & $\begin{array}{l}\text { To assess the level of advance learning and grasp any learning deficit; Grasping } \\
\text { if there is any learning deficit is importance since learners may involve } \\
\text { significant insufficiency in advance learning as they start a class. }\end{array}$ \\
\hline & $\begin{array}{l}\text { Basic } \\
\text { Learning } \\
\text { Supplemental } \\
\text { Course }\end{array}$ & $\begin{array}{l}\text { To make up for the deficit in advance learning grasped through the basic } \\
\text { scholastic ability assessment; Basically, this is only for students. Because of the } \\
\text { class time constraint, it is better to practice supplemental learning for basic } \\
\text { scholastic ability through autonomous MOOC learning instead of the general } \\
\text { class time. }\end{array}$ \\
\hline \multirow{4}{*}{ In-class Step } & $\begin{array}{l}\text { Class Objective } \\
\text { Clarification }\end{array}$ & $\begin{array}{l}\text { To present and make understood learning objectives of the given unit clearly; } \\
\text { Objectives to be achieved in this unit and standards for mastery learning are to } \\
\text { be presented to students. The focus is on helping them recognize the learning } \\
\text { objectives clearly. }\end{array}$ \\
\hline & Class Progress & $\begin{array}{l}\text { To conduct the class; Sufficient opportunities of learning are to be provided with } \\
\text { high learning density maintained. To enhance learners' understanding of the class } \\
\text { content, MOOC videos may be utilized as class materials or as part of the } \\
\text { textbook. }\end{array}$ \\
\hline & $\begin{array}{l}\text { Formative } \\
\text { Assessment }\end{array}$ & $\begin{array}{l}\text { To give feedbacks while the learning/teaching course proceeds and to improve } \\
\text { the curriculum and class delivery; This assessment provides learners with } \\
\text { feedbacks on the learning progress and determines the level of learners with the } \\
\text { class adjusted accordingly. }\end{array}$ \\
\hline & Deep Learning & $\begin{array}{l}\text { Learner-centered activity for learners reaching a certain level of learning to } \\
\text { deepen their understanding of things that they learned; This includes the step of } \\
\text { thinking expansion through practice, actual training, and experiment related to } \\
\text { the class content. }\end{array}$ \\
\hline \multirow{3}{*}{ After-class Step } & $\begin{array}{l}\text { Supplemental } \\
\text { Learning }\end{array}$ & $\begin{array}{l}\text { To provide opportunities of re-learning through MOOC lectures to learners who } \\
\text { have been found in the formative assessment to be slow in learning or fail to } \\
\text { understand the basic knowledge; Aspects to be supplemented in the following } \\
\text { unit are made clear. }\end{array}$ \\
\hline & $\begin{array}{c}\text { Experience- } \\
\text { based Learning }\end{array}$ & $\begin{array}{l}\text { As learners experience thinking expansion during the deep learning process, they } \\
\text { develop creative thinking ability to connect learned knowledge to reality and to } \\
\text { develop ideas with which they can solve actual problems. }\end{array}$ \\
\hline & $\begin{array}{c}\text { Comprehensive } \\
\text { Assessment }\end{array}$ & $\begin{array}{l}\text { To judge the efficiency of class activity by comprehensively assessing the } \\
\text { academic achievement of learners by the time when a class is closed; It is } \\
\text { recommended to conduct comprehensive assessment at the end of each semester } \\
\text { and to reflect the result to the following semester. }\end{array}$ \\
\hline
\end{tabular}

In this step, learners experience freely and proactively both offline and online, which is followed by introspection on the experience. The model designed for the hybrid teaching method is presented in Fig. 1.

Formal learning includes the step of knowledge acquisition and the step of thinking expansion. The step of knowledge acquisition focuses on teachers in the learning process, utilizing the MOOC for the textbook, class materials, and preview/review. As for teacher-centered lectures, it is possible to adjust the level according to the feedbacks of learners and thus to enhance the education effect. Lectures not only help understanding the MOOC but also inducing interest among learners. Thus, the learning process can to learner-centered activity.

The step of thinking expansion presents learnercentered learning activities such as discussion, quiz, and problem-solving. One difference from existing flip learning is that while it is learner-centered but the role of teachers is emphasized. Although activities among learners may enhance learning effect, active intervention of teachers is essential to achieve education objectives within the designated time and to induce passive learners to participate. Teachers need to play the role, not as a mere advisor, but as an active guidance.

The formal on/offline learning is followed by informal learning through which learners practice deep learning or application on the given subject. Learners can have various experiences on a certain topic, both online and offline, and acquire knowledge from those experiences through the step of introspection. During the steps of various experiences and introspection on them, learners may use any form of tools, space, and technology as they want. In informal learning, learners play a leading role while teachers are mere mentors. 


\subsection{Steps of the hybrid teaching method learning model}

The 'Mastery Learning' theory is that as learners understand one learning content completely and move onto the next content, the education objective is regarded as achieved if at least $95 \%$ of the learners take that class. Mastery learning assumes that every learner understands the learning content completely, which is the education objective that the teacher may have in mind. In this model designed for the hybrid teaching method, each step of the class is taken with Blum's mastery learning model as the theoretical basis. Explanations on each step of this hybrid teaching method learning model are presented in Table 1.

The pre-class step includes learners' level assessment and supplemental courses for the basic learning. The in-class step includes clarification of the class objectives, class progress, formative assessment, and deep learning. The after-class includes supplemental learning, experience-based learning, and comprehensive assessment.

According to the Future Education Report, one of the educational techniques to be introduced into higher education within 3 to 5 years is the transition to 'deep approaches to learning.' Deep approaches to learning aim to acquire contents completely through student participation in critical thinking, problemsolving, cooperation, and self-directed learning. If the experience/introspection learning steps are taken, the hybrid teaching method developed in this study will function properly in line with the advancement of educational techniques stated in the above-mentioned report.

\section{Conclusion and Suggestion}

This study is to design a hybrid teaching method that applies lectures of the MOOC to college curriculums, particularly, to basic liberal education. First of all, MOOC lectures are applied to teachercentered lectures in the form of preview/review for knowledge acquisition. Such teacher-centered lectures are followed by various leaner-centered learning programs on the subject, which is the step of thinking expansion. After formal learning, learners may practice informal learning freely based on experience/introspection. Learners may learn by experience proactively both offline and online, going through the step of introspection and origination based on what they experience regarding the obtained knowledge. The hybrid teaching method makes it possible to teach learners according to their levels and present multiple learning steps, pursuing mastery learning.

The role of teachers is far more strengthened in the hybrid teaching method: For both teachercentered lectures and learner-focused activities, teachers play the role of designing the direction of learner activity and guiding the directivity. Because of the time constraint of lectures, the role of teachers in leading learners to the right direction is of importance for learners to acquire knowledge proactively. One major difference from existing blended learning and flip learning is that the role of teachers is emphasized: Teachers need to practice teaching and guidance actively.

Effects expected from applying the hybrid teaching method are as follows:

First, it is possible to adapt to the change in education environment, that is, BYOD (Bring Your Own Device). Recently, BYOD, which utilizes digital devices, is widely used in the field of education. According to one survey, $42 \%$ of the colleges in the U.S. adopt BYOD, which indicates colleges around the globe accept or promote the utilization of mobile devices in a broad range of teaching/learning activities. The hybrid teaching method will be utilizing BYOD naturally in the process of applying the MOOC.

Second, it is possible to balance learning contents with actual objects in daily life. As education is closely related to technical trends, teachers need to provide learners with opportunities to feel, comprehend, introspect, and recognize balanced utilizations of technology by experience. If learners can practice both basic, central, and in-depth learning in the connected state of the MOOC and experiential learning related to daily routines that are not directly connected, the gap between technology and reality will be reduced.

Third, it is more likely to connect the method with augmented reality and virtual reality. Augmented reality and virtual reality have created educational effect in that learners understand and more deeply recognize new perspectives on basic data. While augmented reality and virtual reality are widely utilized in personal media and consumption areas, it is expected that they can be utilized in the area of education as well as using tools for the development of new applications has become easier. The hybrid teaching method will contribute to increasing the possibility of connecting augmented reality and virtual reality with education since it includes the step of experience/introspection learning.

Fourth, affective computing may be utilized. Affective computing is to understand and analyze human emotions. It is expected that in the future, this 
can be utilized to measure the burden of academic tasks and excessive schedules among learners. As the hybrid teaching method is applied, connecting online lectures of the MOOC with offline learning will reduce the level of fatigue syndrome that learners may suffer from, and it will be possible to measure the effect by means of affective computers.

It is expected that basic liberal education can take the lead of future education trends such as customized learning in line with the science technology advancement, demolition of the spatial border between online and offline areas, emphasis on the connectivity between theories and reality through formal and informal learning, and so forth, in utilization of the hybrid teaching method and its MOOC.

\section{Acknowledgments}

This study was conducted as an assignment of Korea National Institute for General Education under the Korean Council for University Education.

\section{References}

[1] A. Fidalgo-Blanco, M. Sein-Echaluce, and F. García-Peñalvo, "From massive access to cooperation: lessons learned and proven results of a hybrid xMOOC/cMOOC pedagogical approach to MOOCs", International Journal of Educational Technology in Higher Education, Vol.13, No.1, pp.1-13, 2016.

[2] P.J. Guo, J.H. Kim, and R. Rubin, "How video production affects student engagement: An empirical study of MOOC videos", In: Proc. of the first ACM conference on Learning scale conference, pp. 41-50, 2014.

[3] M.S. Lee, "Report on the status of e-learning in 2015", Korea Education \& Research Information Service, pp. 45-51, 2016.

[4] J.W. Jeong, "Analyzing learning experience and perception in a blended entrepreneurship training program: A case study", The Korean Association for Educational Methodology Studies, Vol. 26, No. 4, pp.871-898, 2014.

[5] H. J. Jeong and I. E. Kang, "Study of the development of learner centered PBL(LC PBL) model in higher education", Korean Association for Learner-centered Curriculum and Instruction, Vol. 11, No. 4, pp.419-448, 2011.

[6] S. B. Cha, S.Y. Park, and B.D Ku, "An analysis of the relationship between university students informal learning outcomes with social acceptance, participation, perceived attitude and subjective knowledge based on the structural equation model", Korean Association for
Educational Information and Media, Vol.20, No.4, pp. 675-704, 2014.

[7] $\mathrm{KOCW}$, http://www.kocw.net/home/kocwStatistics.do.

[8] Bloom's Mastery Learning Model, http://blog.naver.com/ 1llmanill1/140146310190. 